\title{
A Relational Perspective on PTSD in Early Childhood
}

Michael S. Scheeringa ${ }^{2,3}$ and Charles H. Zeanah ${ }^{2}$

${ }^{2}$ Tulane University School of Medicine, Department of Psychiatry and Neurology. Section of Child and Adolescent Psychiatry, New Orleans, Louisiana.

${ }^{3}$ To whom correspondence should be addressed at 1440 Canal Street, TB52, New Orleans, Louisiana 70112; e-mail: mscheer@tulane.edu.

This is a post-print, author-produced PDF of an article accepted for publication in the Journal of Traumatic Stress following peer review and allowed to be disseminated under JTS policy. The definitive publisher-authenticated version (Scheeringa MS, Zeanah CH (2001). A relational perspective on PTSD in early childhood. Journal of Traumatic Stress, 14(4):799-815.) is available online at: https://doi.org/10.1023/A:1013002507972.

This work is licensed under a Creative Commons Attribution 4.0 International License.

\begin{abstract}
This paper describes the clinical and research evidence for the importance of the relational context of posttraumatic stress disorder in young children. We review 17 studies that simultaneously assessed parental and child functioning following trauma. In many studies, despite limitations, an association between undesirable parental/family variables and maladaptive child outcomes has been consistently found. We present a model of the parental/family variables as moderators and vicarious traumatic agents for symptoms in young children. Also, a Compound Model is proposed, with three distinctive patterns of the parent-child relationship that impact on posttraumatic symptomatology in young children. Implications for clinical practice and research directions are discussed.
\end{abstract}

KEY WORDS: posttraumatic stress disorder; children; preschool; relationship.

\section{Introduction}

A central question for understanding psychopathology in young children is the degree to 
which symptomatology and disorders in the early years are similar to or distinct from their manifestations in older children and adults. Several features of development have been noted to be distinctively different in the first 3 years of life and likely to influence how psychopathology is expressed and experienced by young children (Zeanah, Boris, \& Scheeringa, 1997). First, the less developed cognitive, perceptual, and linguistic capacities of young children seem bound to influence how young children experience and respond to various risks for psychopathology. Second, the pace of developmental change is rapid in the first 3 years of life, with development proceeding generally from less differentiated to more differentiated levels of complexity. This suggests that manifestations of clinical disturbances may be less well differentiated in young children or even change over time in response to children's maturation. Third, the usual measurement problems in psychiatry and psychology are compounded in early childhood when assessments of clinical symptomatology cannot include children reporting their own subjective experiences. From whom to obtain and how to evaluate differing reports of infant behavior and disturbance are vexing questions. Finally, the importance of the infant-caregiver relationship as a central feature of psychopathology in infancy has been emphasized increasingly (Crockenberg \& Leerkes, 2000; Lyons-Ruth, Zeanah, \& Benoit, 1996; Zeanah, Larrieu, Heller, \& Valliere, 2000).

In this paper, we focus on the relational context of posttraumatic stress disorder (PTSD) in early childhood. Initially, we describe the importance of the infant's primary caregiving relationships as influences on development. Next, we review research suggesting that these relationships are central to expressions of posttraumatic symptomatology throughout childhood and adolescence. We then present a model to illustrate how the primary caregiving relationship may be central to the expression of posttraumatic symptomatology in young children.

\section{Relationship Context of Infancy}


The importance of the parent-child relationship for normal social and emotional development is well-established. Numerous studies have documented that individual differences in infant-parent interaction are predictive of subsequent child social and emotional adaptation (Crockenberg \& Leerkes, 2000; Zeanah, Boris, \& Scheeringa, 1997). For example, insecurity in the attachment relationship at 12 months of age predicts childhood behavior problems (Fagot \& Kavanagh, 1990) and even adolescent anxiety disorders (Warren, Huston, Egeland, \& Sroufe, 1997). In fact, important domains of child development are predictable from characteristics of parents measured even before their children are born (Heinecke, Diskin, Ramsey-Klee, \& Oates, 1986). For example, the quality of attachment that mothers and fathers reported with their own parents when measured in the last trimester of pregnancy predicted the quality of attachments that developed between each parent and the respective infant when the infants were 1 year of age (Steele, Steele, \& Fonagy, 1996). Also, mothers' perceptions about their unborn child in the third trimester of pregnancy predicted significantly the observed mother- child attachment relationship measured at 12 months of age (Benoit, Parker, \& Zeanah, 1997). Further, various environmental risk conditions such as poverty, parental mental illness, or adolescent parenthood are experienced by young children through their primary caregiving relationships (Zeanah, Boris, \& Larrieu, 1997). Individual differences in infant-parent relationships within these broad risk conditions are also related to differences in subsequent child outcomes (Seifer \& Dickstein, 2000). Even relationship disruptions that are temporally limited, such as maternal depression, may lead to more behavioral problems in the children (e.g., Murray, 1992). Interventions designed to improve parent-child relationships have been demonstrated to improve child outcomes (McCarton, Brooks-Gunn, Wallace, \& Bauer, 1997; Olds et al., 1998). All of this suggests that attention to the infant-parent relationship is important for infant development and 
psychopathology (Zeanah et al., 2000).

\section{Relationship Context of Stress}

The evidence for the importance of the infant-caregiver relationship also derives from studies of stress. Because young children cannot manage threat on their own, they are dependent upon their discriminated attachment figures to provide them with protection. Further, infants' regulatory functions, including their stress-response systems, are dependent upon their relationships with their primary caregivers (Polan \& Hofer, 1999; Kraemer, 1992). Experimental manipulation of caregiver responsiveness in the face of threat to the infant has been shown to be related to cortisol secretion. Infants who were separated from the mother for 30 min and left with responsive substitute caregivers (trained research assistants) failed to produce increases in levels of cortisol, whereas cortisol increased and correlated with negative affect in infants who were left with minimally responsive substitute caregivers (Gunnar, Larson, Hertsgaard, Harris, \& Broderson, 1992). More importantly, secure attachment to the primary caregiver has been shown to moderate the effects of stress on cortisol responses in vulnerable (behaviorally inhibited) infants (Nachmias, Gunnar, Mangelsdorf, Parritz, \& Buss, 1996). These and related findings underscore the importance of the primary caregiving relationship for management of threat and stress in young children.

Some stressful experiences for young children are traumatic and may lead to psychiatric symptomatology. This raises the question of whether or not young children can experience PTSD. Recently, the validity of the diagnosis of PTSD in infants and toddlers has been studied systematically both in published case reports and in studies of clinic-referred, traumatized children (Scheeringa, Peebles, Cook, \& Zeanah, 2001; Scheeringa \& Zeanah, 1995; Scheeringa, Zeanah, Drell, \& Larrieu, 1995). This work has established that children less than 4 years of age 
often develop posttraumatic symptomatology following exposure to trauma. Further, the classic triad of reexperiencing symptoms, numbing/avoidance symptoms, and hyperarousal symptoms are demonstrable in young children, although discerning their presence in preverbal children may be difficult. For example, reenactment of the traumatic event in play is more likely than reports of "flashbacks" in young children.

This work led to the creation of an alternative set of criteria for PTSD for infants and young children published in the Diagnostic Classification: 0-3 (DC: 0-3) (Zero to Three, 1994). These criteria were modified in two important ways. First, some of the criteria in the DSM-IV version were too dependent on describing the internal thoughts and feelings of patients. Young children with limited verbal and abstract cognitive capacities cannot yet express their internal experiences. Therefore, some items were deleted, such as foreshortened sense of the future and partial amnesia for the event. Other items had to be modified to be less dependent on verbalizations and more dependent on behavioral observations of the children (e.g., an increased frequency of nightmares is sufficient regardless if the child is able to verbalize the content). Second, the DC: 0-3 criteria contain new items that are more developmentally sensitive to this age group. The items "new separation anxiety," "new aggression," "loss of previously acquired developmental skills (such as toileting and speech)," and "new fears unrelated to the trauma" (such as fear of entering the bathroom alone) were added. In addition, other items were modified to reflect appropriate developmental levels, such as noting that play is the main significant activity for which patients may lose interest.

\section{The Relationship Context of PTSD: A Review of Studies}

The association between maternal functioning and children's symptoms following trauma was first documented over 50 year ago. Carey-Trefzer (1949) reviewed the charts of children 
who attended a mental health clinic in London and who had been exposed to air raids and evacuations during World War II. Children who had nervous parents had more persisting emotional and behavioral problems related to their war experiences. Bloch, Silber, and Perry (1956) provided another historically important study on children and their families following a tornado. We reviewed all of the known subsequent studies of parent and child adjustment following traumatic events. The inclusion criteria for studies in this review were that (a) the children had been exposed to a DSM -IV-level trauma (threatened death or serious injury or a threat to the physical integrity of self or others; American Psychiatric Association, 1994), (b) the children and parents were assessed concurrently, and (c) the study included measures that were standardized and replicable. Seventeen studies met these criteria and are summarized in Table l. Rigorous comparison of these studies is limited because of the heterogeneity among the studies for the type of trauma, study design, measurement techniques, and outcome variables. Nonetheless, all but one of these studies found a significant association between less adaptive parental functioning and less adaptive child functioning following traumas. The lone exception was the study by Kilpatrick and Williams (1998), which was a small cross-sectional study of children who witnessed domestic violence. Rather than describe each individual study, we will summarize the overall findings and then critique the strengths and weaknesses of these studies in terms of study design, measurement technique, and outcome variables.

Overall, the child outcomes that were associated with poorer parental/family adjustment included higher rates of PTSD (Famularo, Fenton, Kinscherff, Ayoub, \& Barnum, 1994; Pelcovitz et al., 1998; Sack, Clarke, \& Seeley, 1995), increased number of PTSD symptoms (Ajdukovic, 1998; Breton, Valla, \& Lambert, 1993; Deblinger, Steer, \& Lipmann, 1999; Koplewicz et al., 1994; Laor, Wolmer, Mayes, \& Gershon, 1997; McFarlane, 1987; Rossman, 
Bingham, \& Emde, 1997; Ruchkin, Eisemann, \& Haeggloef, 1998; Wasserstein \& LaGreca, 1998), elevated CBCL internalizing score (Deblinger et al., 1999; Laor et al., 1996; Rossman et al., 1997), elevated CBCL externalizing score (Deblinger et al., 1999; Laor et al., 1996; Rossman et al., 1997), poorer score on the CBCL social competence scale (Rossman et al., 1997), increased depression score (Deblinger et al., 1999), elevated Behavior Screening Questionnaire score (Comely \& Bromet, 1986), and elevated teacherrated aggression and antisocial behavior (Burke, Borus, Bums, Millstein, \& Beasley, 1982). The parental/family variables that were associated with worse child outcomes included higher rates of PTSD (Famularo et al., 1994; Pelcovitz et al., 1998; Sack et al., 1995), elevated number of PTSD symptoms (Koplewicz et al., 1994; Rossman et al., 1997), increased parental anxiety since the events (Ajdukovic, 1998), wide variation between the mother's and father's reactions (Handford et al., 1986), elevated BDI scores (Deblinger et al., 1999), elevated maternal score on the SCL-90 (Comely \& Bromet, 1986; Laor et al., 1996, 1997), increased general psychiatric problems in either parent (Breton et al., 1993), family breakup (McFarlane, 1987), overprotectiveness (McFarlane, 1987), increased irritability and withdrawal within the family (McFarlane, 1987), inadequate family cohesion (Laor et al., 1996), increased family chaos (Pelcovitz et al., 1998), increased parental conflict (Wasserstein \& LaGreca, 1998), less supportiveness of the child (Rossman et al., 1997), perceived as rejecting (Deblinger et al., 1999; Ruchkin et al., 1998 [father only]\}, perceived as inducing guilt and anxiety (Deblinger et al., 1999), father perceived as low on warmth (Ruchkin et al., 1998), denial or suppression of awareness of their children's symptoms (Burke et al., 1982; Handford et al., 1986), and history of any maternal psychiatric disorder (Comely \& Bromet, 1986). 
The most precise parental variables that may illuminate the parent-child dynamics was the finding that the avoidance symptom was the only maternal variable to predict significantly worse child outcome in one regression analysis (Laor et al., 1997). Also, inducing guilt and anxiety, and perceived rejection by the parents are relatively specific behaviors that led to worse child outcomes in another study (Deblinger et al., 1999).

All of these studies sampled cohorts that were either similar on exposure to the same traumatic event, such as a tornado or flood, or to the same type of trauma, such as sexual abuse or atrocities in Cambodia. Twelve of the studies sampled cohorts irrespective of whether they showed symptoms, whereas four studies used selective sampling strategies that were likely to be biased toward more symptomatic children (Deblinger et al., 1999; Famularo et al., 1994; Rossman et al., 1997; Ruchkin et al., 1998). The sampling strategies of Ajdukovic (1998) and Kilpatrick and Williams (1998) were not adequately described.

Fourteen of the studies were cross-sectional one-time assessments. The remaining three studies used the relatively stronger design of prospective, multiple time-point assessments. McFarlane (1987) showed that parent and family variables assessed at 2, 8, and 26 months following an Australian bushfire consistently associated with elevated PTSD symptoms in the children. Koplewicz et al. (1994) showed that elevated parental PTSD symptoms correlated with elevated children's PTSD symptoms 9 months after the World Trade Center bombing, but not 3 months after. Lastly, Laor et al. (1997) showed that both maternal general psychiatric symptomatology (SCL-90) and maternal intrusive thoughts associated with elevated PTSD symptoms in 3- and 4-year-old children 30 months after SCUD missile attacks in Israel but not at 6 months. This association was not found in the 5-year-old children. In addition, increased avoidance in the mothers associated with elevated child PTSD 
scores in the 3-year-olds, but not the 4- and 5-year-old children.

Overall, these studies included a variety of combinations of child self-report, parent self-report, parent-report-on-child, and interviewer-based tools for the assessment of children, parents, and family functioning. The assessment tools for the children's functioning included standardized diagnostic interviews of both parent and child in four studies, standardized diagnostic parental interview plus parent-report checklists in two studies, parental interview only in one study, parent checklists only in three studies, standardized diagnostic child interview only in two studies, both parent-report and childreport checklists in one study, and child-report only in four studies. The assessment tools for the parental functioning included standardized diagnostic parent interview plus parent selfreport checklists in three studies, standardized diagnostic parent interview in two studies, parent self-report checklists only in seven studies, idiosyncratic measures in two studies, interview of child in one study, and child report only in two studies.

The strongest measurement technique for assessment of clinical level problems is interviewer-based tools for both child and parent, which was the case in only three studies. Famularo et al. (1994) showed that higher rates of PTSD in mothers associated with higher rates of PTSD in children in a selective sample of families brought before a court for maltreated children. Fathers were not assessed. Pelcovitz et al. (1998) showed the same finding in a cohort of adolescents treated for cancer. Sack et al. (1995) showed a similar relationship for both mothers and fathers in a sample of randomly selected Cambodian refugees in two American cities. Sack et al. also showed a gradient effect of parental PTSD predicting higher rates of child PTSD. When no parent had PTSD, 12.9\% of the children had PTSD. When one parent had PTSD, 23.3\% of the children had PTSD. When both parents had PTSD, the 
percentage for children jumped to $41.2 \%$.

Only five studies assessed for the full PTSD disorder, nine studies assessed for a portion of the PTSD criteria, and three studies used a variety of standardized parent- (and sometimes teacher-) report checklists for non-PTSD variables. All of the 15 studies that assessed for PTSD disorder or symptoms showed significant associations to one or more parental/family variables except for the Kilpatrick and Williams (1998) study. Non-PTSD outcome variables that were associated with worse parental/family functioning were increased aggression, increased antisocial acts (Burke et al., 1982), elevated Behavior Screening Questionnaire (Richman \& Graham, 197 I) scores (Comely \& Bromet, 1986), elevated CBCL internalizing scores (Deblinger et al., 1999; Laor et al., 1996), elevated CBCL externalizing scores (Deblinger et al., 1999; Laor et al., 1996), elevated Preschool Children's Assessment of Stress Scale (Laor et al.,1996), elevated Revised Children's Manifest Anxiety Scale (Reynolds \& Richmond, 1978) score (Wasserstein \& LaGreca, 1998), and elevated depression score (Deblinger et al., 1999). Despite the heterogeneity of measures used for assessment, there is a clear pattern for a relational link between parental and family functioning and child functioning following trauma. In fact, the heterogeneity of measures strengthens the case for a relational link precisely because of the consistency of the association across virtually all studies no matter which measures of functioning have been used.

The relational aspects of posttrauma adjustment may be most salient in infant and preschool children because of their relatively greater dependence on caregivers. The three studies that exclusively studied this population (Comely \& Bromet, 1986; Laor et al., 1996, 1997) all found significant associations between poorer maternal or family functioning (or both) and worse child outcomes. Interestingly, when Laor et al. (1997) 
analyzed their sample by age they continued to find these significant associations for the 3- and 4-year-old children but not for the 5-year-old children. An additional study worth noting (Scheeringa \& Zeanah, 1995) examined traumatized preschool children and the variables that may be predictive of the level of severity of posttraumatic symptomatology. Forty-one cases of traumatized children less than 4 years of age were analyzed to determine whether six child- and trauma-related variables were associated with higher rates of PTSD and greater severity of posttraumatic symptomatology. The six variables included acute/single trauma versus chronic/repetitive trauma, child injured versus not injured in the event, the child only witnessed the event versus having directly experienced the event, the child's caregiver was threatened in the event versus not threatened, the child was younger than 18 months at the time of the trauma versus 18 months or older, and gender. The variable that best predicted severity of symptomatology, and the only variable associated with significantly higher rates of PTSD, was that the trauma involved threats to the children's caregivers.

This association may be understood in two different ways. First, it may be that the children experienced a direct threat because they appreciated the implications of the threat to the caregiver, and this direct threat led to increased posttraumatic symptomatology. Alternatively, caregivers may be traumatized by the same event as the child, and this may compromise the care that they provide to their child. This might result in a secondary increase in posttraumatic symptomatology because the caregiver is less available to respond sensitively to the child's symptomatology.

\section{Relationships and Traumas: Types of Effects}

In order to consider the means by which parent and child posttraumatic 
symptomatology may be associated, we will consider several types of effects.

\section{Minimal Effect}

For reasons that are unclear, some individuals exposed to traumatic events are affected and others are not. In fact, estimates in adults are that the majority of traumaexposed individuals do not develop PTSD. For example, in the National Comorbidity Survey, only $20 \%$ of exposed women and $8 \%$ of exposed men developed PTSD (Kessler, Sonnega, Bromet, Hughes, \& Nelson, 1995), although this percentage varied depending on the type of trauma. Similar figures have been found in older children and adolescents (e.g., Widom, 1999). There are no comparable data available for young children, although we may hypothesize that younger age may increase or decrease vulnerability to traumatic experiences. For example, less mature cognitive appraisal abilities may lead young children to underestimate or fail to recognize some threatening situations as dangerous, such as an adult pulling out a gun in a convenience store. On the other hand, less dangerous events, such as a noisy lawn mower, may prove extremely frightening to young children who lack the ability to understand the meaning of perceptual stimuli they encounter (see Drell, Siegel, \& Gaensbauer, 1993).

Moderating Effect

A possible effect on the young child-parent relationship following trauma is similar to the statistical term "moderator." Baron and Kenny (1986) define a moderating variable as one that affects the direction or strength (or both) of the relation between an independent variable and a dependent variable. In the Moderating Effect model, the mother's relationship with the child (including her ability to read his/her cues and respond effectively to his/her needs) affects the strength of the relation between the traumatic event 
(independent variable) and the child's symptomatic responses (dependent variable). In this model, there is an a priori adverse effect anticipated between the traumatic event and the child's symptoms (because the child experienced the event directly), but the magnitude of the ad- verse effect may be intensified or reduced by the mother's responses to the child. Mothers may or may not be traumatized by the same event as the child. The key issue is the degree to which the mother can accurately read and understand her child's symptomatology. As noted earlier, mothers experiencing the symptom of avoidance of reminder8 of the trauma may limit their ability to respond to play reenactments or even to discuss traumatic events with their children. The few studies that have addressed this question directly in young children have confirmed that avoidance in mothers and insensitive responsiveness are strongly related to worse outcomes in young children (Deblinger et al., 1999; Laor et al., 1997). In these situations, the mother-child relationship moderates the effect of the trauma on the young child's adaptation.

\section{Vicarious Traumatization Effect}

Another possible effect on the young child-parent relationship is a model in which a mother (usually) experienced a traumatic event but the child did not. The mother's relationship with the young child, including her own symptomatology and its effect on her responsiveness to the child, accounts for the effect of the traumatic event (which the child did not experience directly) and the child's symptomatology. That is, if not for the young child-mother relationship, there would be no effect of the trauma on the child. Intense posttraumatic symptomatology certainly can preoccupy a mother to the point that her ability to monitor and respond effectively to her young child is impaired. Specific effects in the child depend upon the nature of the effects on the caregiver. For example, Terr (1990) has reported a case of a 4- 
year-old girl who claimed to have visual memories of her old sister's accident 2 years earlier even though she did not witness it. The girl's memories were a composite of the family member's memories that she had gathered by listening to family stories about the event. Compound Effect

In the compound effect, there is a combination of moderating and vicarious traumatization effects. That is, both caregiver and child are traumatized, and the symptomatic behavior of each partner exacerbates that of the other. Infants are directly affected by the traumatic event, and their symptomatology is exacerbated by the indirect effect of their caregiver's compromised responsiveness to them, which is in part a result of the caregiver's own posttraumatic symptomatology. Reading the infant's cues, understanding their behavior, and responding to them effectively all are compromised in the compound effect. Because young children are so dependent upon their adult caregiver's sensitive responsiveness, when

young children are symptomatic, they are especially vulnerable to insensitivity in the caregiver created by the adult's posttraumatic symptomatology.

\section{Relational PTSD Patterns}

We propose the construct of Relational PTSD to describe the Compound Effect, that is, the co-occurrence of posttraumatic symptomatology in an adult caregiver and a young child when the symptomatology of one partner, usually the adult, exacerbates the symptomatology of the other. The child and parent may be traumatized by the same event or by different events, but the effects of each partner's symptomatology exacerbate the other's. The child's symptoms may range from moderate to severe, but they appear to be substantially intensified by the relation- ship with the caregiver. Below, we describe and illustrate three specific patterns. 


\section{Withdrawn/Unresponsive/Unavailable Pattern}

Traumatized adults with either acute or chronic PTSD may be significantly less available to their young children because of their own impairments. Avoidance and withdrawal symptoms in acutely traumatized adults especially may limit reading and responding sensitively to a young child who is similarly traumatized. Chronically traumatized adults are quite likely to be compromised as caregivers for their young children. When parents are emotionally and functionally unavailable for their children, it is likely that their children's symptomatology will be exacerbated.

This pattern appears to occur most commonly in mothers who have suffered previous trauma themselves, and their children's traumas reawaken painful memories and emotions that they would rather avoid. Comorbid disorders of depression, or complicated grief, also may reduce the adult caregiver's ability to monitor the child's needs and symptoms. In these situations, the child's symptomatology usually derives from a fairly recent event, whereas the mother's trauma was either chronic or at least in the more remote past.

\section{Overprotective/Constricting Pattern}

Following exposure of a young child to a trauma, parents may become constrictive and overprotective, preoccupied by fear that their child may be traumatized again. Overprotectiveness, of course, may occur independent of the child's exposure to trauma, but in our experience, it is one possible response to traumatization. In these cases, the change in parenting style will be temporally related to the traumatic experience. Further, the pattern will be persistent and tend to resist any efforts to suggest that it is unwarranted or excessive. Although this pattern may be manifest in cases in which the parent was present and traumatized by the same experience as the young child, it is also possible for the parent to 
be traumatized even when not present at the traumatic event. Often guilt about not being present to protect the child during the traumatic event may be involved. The parent, in such cases, may reconstruct an imagined scene of the child being traumatized and then reexperience that scene intrusively. Reenacting/Endangering/Frightening Pattern

Some adults respond to traumas by becoming preoccupied with reminders of the trauma rather than avoiding them. If a traumatized parent repeatedly asks questions or discusses the traumatic event, this unwelcome preoccupation in the parent may retraumatize a young child. At the simplest level, a parent may be so intensely preoccupied as to be unable to censor his/her own statements or behavior to shield the child. For example, we described briefly a case of a mother who persistently prodded her child to tell her more details of a sexual molestation episode (Zeanah \& Scheeringa, 1996). However, we did not report earlier how extremely distressed this child became from these interrogations. Sometimes this mother would threaten to call the police to take the boy away if he did not tell her more. Having already told her all he knew he would cry in a corner until she stopped. One may further speculate that a preoccupied caregiver may unconsciously place her child in dangerous situations in which further traumas are actually more likely to occur. Although documentation has never been provided about the inner thoughts and motivations of a caregiver in such a case, we propose this as a plausible explanation for some cases where children suffer an unusually high number of traumas, such as in one reported case of a child who experienced seven traumatic events (Osofsky \& Scheeringa, 1997).

\section{Discussion}

The evidence summarized in this paper indicates that the nature and quality of parent- 
child relationships matter profoundly for all young children, and perhaps uniquely for young children who experience traumatic events. We offered the construct of Relational PTSD to describe the influence of the parent-child relationship on the posttrauma symptomatology of children. We hope that recognition of these patterns provides salient information for clinical assessment and treatment.

The clinical implications for evaluation and treatment are clear. As with most other forms of psychopathology in young children, posttraumatic symptoms are most usefully considered within the context of the parent-child relationship. Various approaches to infantcaregiver relationship assessment have been described (Clark, Paulsen, \& Conlin, 1993; Zeanah et al., 2000), and they share a dual focus on both the interactional behaviors and the subjective experiences of the dyadic partners.

In the case of traumatized young children, it is important to attend first to the caregiver's symptomatology and only then to the child's symptoms. There are several reasons why this is so. First, the most powerful potential change agent for young children's development and symptomatology is their relationship with their primary caregiver (Crockenberg \& Leerkes, 2000; Lyons-Ruth et al., 1996; Zeanah, Boris, \& Larrieu, 1997). Therefore, making strategic changes in the nature of the primary caregiving relationship represents the best opportunity for making changes in the behavior and symptomatology of the young child who is far less likely to respond to individually directed treatments. Second, a sustained change in parent's symptomatology is likely to make them better able to respond sensitively to the needs of their children. This was illustrated, for example, in a case report of two young children who witnessed their mother murdered (Pruett, 1979). The grandmother who took in the children frequently broke down into tears 
and the children ended up comforting her. This situation was reversed fortunately with the aid of a therapist. Third, since young children and their caregivers are often together when traumatizing events occur, they may both be affected profoundly by these events. If parents become symptomatic, particularly if they are avoidant of reminders of the trauma, they may find it difficult to be present when a young child reenacts the experience in play. Such was the case, for example, in two reports published on the same case of a boy who had been mauled by a leopard in a pet shop (MacLean, 1977, 1980). The need for the second case report was to illustrate the critical importance of treating the parents in order for the child to recover, a dynamic that had been overlooked in the first report. Finally, as we have described, primary caregivers are uniquely important contextually as central aspects of the young child's experience of traumatic events because of the importance of the parent-child relationship for current and subsequent adaptation. This concept has been empirically supported for the quality of attachments (Steele et al., 1996), childhood behavior problems (Fagot \& Kavanagh, 1990; Murray, 1992), and adolescent anxiety disorders (Warren, Huston, Egeland, \& Sroufe, 1997).

We also propose that this model is useful for generating testable research hypotheses for several areas in the study of posttraumatic reactions and treatment in children, particularly for infants and preschool children. First, the literature on the treatment of young traumatized children, which consists almost entirely of case reports (e.g., MacLean, 1977; Pruett, 1978; Zeanah \& Burk, 1984; and see Scheeringa, 1999, for overview), converges with a relational perspective. However, PTSD treatment efficacy studies have yet to test separately the effects of treating child only, parent only, and parent and child concurrently. Second, it is not entirely clear yet whether the salient parental reaction is trauma-specific, as in PTSD-style 
intrusive thoughts and avoidance symptoms, or due to any type of psychiatric symptomatology that impairs parental supportiveness to the child. Third, the identification of an association between parent and child outcomes is not sufficient to proclaim a causal association between parent and child. The mechanism of how parental functioning impinges on child adaptation must be more fully explored with more finer-grained, longitudinal analysis of parent-child interaction following trauma. In vivo observation in naturalistic settings may be required for certain research questions. Fourth, in addition to identifying the qualitative pattern of parental behavior, or mechanism, that is salient, it will be useful to quantify the dose required to achieve a clinical impact on children at different developmental levels. Lastly, genetic factors cannot be ruled out yet as explanatory factors for the association between parental and child symptoms. The fact that children and parents in the same families show elevated posttraumatic symptoms may be due to a shared genetic vulnerability rather than parent-child dynamics. Finally, posttraumatic symptomatology in young children that is best understood in a relational context should not be confused with "mother-" or "parentblaming." Young children experience a variety of positive and negative stressors under the watchful eyes of their caregivers. They will navigate these stressors in large part based upon the nature of their primary caregiving relationships. Further, parents are likely to be the most important and useful agents of change to aid their children's recovery. And, if parents' responses are complicating or impeding children's recovery, then dyadic interventions are clearly indicated.

In summary, we propose that understanding young children's traumatic responses in the context of their primary caregiving relationships provides the best opportunity to develop appropriate and effective interventions for them. With this understanding, it is likely that the 
harmful effects of traumatic experiences will be limited both for young children and for their caregivers.

\section{References}

Ajdukovic, M. (1998). Displaced adolescents in Croatia: Sources of stress and posttraumatic stress reaction. Adolescence, 33, 209-217.

American Psychiatric Association (1994). Diagnostic and statistical manual of mental disorders (4th ed.). Washington, DC: American Psychiatric Association.

Baron, R. M., \& Kenny, D. A. (1986). The moderator-mediator variable distinction in social psychological research: Conceptual, strategic, and statistical considerations. Journal of Personality and Social Psychology, 51, 1173-1 182.

Benoit, D., Parker, K., \& Zeanah, C. H. (1997). Mothers' representations of their infants assessed prenatally: Stability and association with infants' attachment classifications. Journal of Child Psychology, Psychiatry and Allied Disciplines, 38, 307-313.

Bloch, D. A., Silber, E., \& Perry, S. E. (1956). Some factors in the emotional reaction of children to disaster. American Journal of Psychiatry, 113, 416-422.

Breton, J. J., Valla, J. P., \& Lambert. J. (1993). Industrial disaster and mental health of children and their parents. Journal of the American Academy of Child and Adolescent Psychiatry, 32. 438- 445.

Burke, J. D., Borus, J. F., Bums, B. J., Millstein, K. H., \& Beasley, M. C. (1982). Changes in children's behavior after a natural disaster. American Journal of Psychiatry, 139, 1010-1014. 
Carey-Trefzer, C. J. (1949). The results of a clinical study of war-damaged children who attended the child guidance clinic, The Hospital for Sick Children, Great Ormond Street, London. Journal of Mental Science, 95. 535-559.

Clark, R., Paulsen, A., \& Conlin, S. (1993). Assessment of developmental status and parent-infant relationships: The therapeutic process of evaluation. In C. H. Zeanah (Ed.), Handbook of infant mental health (pp. 191-209). New York: Guilford Press.

Comely, P., \& Bromet, E. (1986). Prevalence of behavior problems in three-year-old children living near Three Mile Island: A comparative analysis. Journal of Child Psychology and Psychiatry, 27, 489-498.

Crockenberg, S., \& Leerkes, E. (2000). Infant social and emotional development in family context. In C. H. Zeanah (Ed.), Handbook of infant mental health (2nd ed., pp. 6090). New York: Guilford Press.

Deblinger, E., Steer, R., \& Lipmann, J. (1999). Maternal factors associated with sexually abused children's psychosocial adjustment. Child Maltreatment: Journal of the American Professional Society on the Abuse of Children, 4, 13-20.

Drell, M. J., Siegel, C. H., \& Gaensbauer, T. J. (1993). Post-traumatic stress disorder. In C. H. Zeanah (Ed.), Handbook of infant mental health (pp. 291-304). New York: Guilford Press.

Fagot, B. L., \& Kavanagh, K. (1990). The prediction of antisocial behavior from avoidant attachment classifications. Child Development, 61, 864-873.

Famularo, R., Fenton, T., Kinscherff, R., Ayoub, C., \& Barnum, R. (1994). Maternal and child posttraumatic stress disorder in cases of child maltreatment. Child Abuse and Neglect, 18. 27-36. 
Gunnar, M. R., Larson, M. C., Hertsgaard, L., Harris, M. L., \& Broderson, L. (1992). The stressfulness of separation among nine-month-old infants: Effects of social context variables and infant temperament. Child Development, 63, 290-303.

Handford, H. A., Mayes, S. D., Mattison, R. E., Humphrey, F. J., Bagnato, S., Bixler, E. 0.,\& Kales, J. D. (1986). Child and parent reaction to the Three Mile Island nuclear accident. Journal of the American Academy of Child Psychiatry, 25, 346-356.

Heinecke, C. M., Diskin, S. D., Ramsey-Klee, D. M., \& Oates, D. S. (1986). Pre- and postbirth antecedents of 2-year-old attention, capacity for relationships, and verbal expressiveness. Developmental Psychology, 22, 777-787.

Kessler, R. C., Sonnega, A., Bromet, E., Hughes, M., \& Nelson, C. B. (1995). Posttraumatic stress disorder in the National Comorbidity Survey. Archives of General Psychiatry, 52. 1048-1060.

Kilpatrick, K. L., \& Williams, L. M. (1998). Potential mediators of post-traumatic stress disorder in child witnesses to domestic violence. Child Abuse and Neglect, 22, 319330.

Koplewicz, H. S., Vogel, J. M., Solanto, M. V., Morrissey, R. F., Alonso, C. M., Gallagher, R., Abikoff, H. B., \& Novick, R. M. (1994, October). Child and parent response to the World Trade Center bombing. Poster session presented at the American Academy of Child and Adolescent Psychiatry, New York City.

Kraemer, G. W. (1992). A psychobiological theory of attachment. Behavioral and Brain Sciences, 15,493-541.

Laor, N., Wolmer, L., Mayes, L. C., \& Gershon, A. (1997). Israeli preschool children under scuds: A 30-month follow-up. Journal of the American Academy of Child and 
Adolescent Psychiatry, 36, 349-356.

Laor, N., Wolmer, L., Mayes, L. C., Golomb, A., Silverberg, D.S., Weizman, R., \& Cohen, D. J. (1996). Israeli preschoolers under Scud missile attacks. Archives of General Psychiatry, 53, 416-423.

Lyons-Ruth, K., Zeanah, C. H., \& Benoit, D. (1996). Disorder and risk for disorder during infancy and toddlerhood. In E. J. Mash \& R. A. Barkley (Eds.), Child psychopathology (pp. 457-491). New York: Guilford Press.

Maclean, G. (1977). Psychic trauma and traumatic neurosis: Play therapy with a four-year-old boy. Canadian Psychiatric Association Journal, 22, 71-75.

MacLean, G. (1980). Addendum to a case of traumatic neurosis: Consideration of family dynamics. Canadian Journal of Psychiatry, 25, 506-508.

McCarton, C. M., Brooks-Gunn, J., Wallace, I.F., \& Bauer, C. R. (1997). Results at age 8 years of early intervention for low-birth-weight premature infants: The infant health and development program. JAMA, 277. 126-132.

McFarlane, A. C. (1987). Posttraumatic phenomena in a longitudinal study of children following a natural disaster. Journal of the American Academy of Child and Adolescent Psychiatry, 26, 764- 769.

Murray, L. (1992). The impact of postnatal depression on infant development. Journal of Child Psychology and Psychiatry, 33, 543-561.

Nachmias, M., Gunnar, M., Mangelsdorf, S., Parritz, R., \& Buss, K. (1996). Behavioral inhibition and stress reactivity: The moderating role of attachment security. Child Development, 67, 508- 522.

Olds, D., Henderson, C., Kitzman, H., Eckenrode, J., Cole, R., \& Tatelbaum, R. (1998). The 
promise of home visitation: Results of two randomized trials. Journal of Community Psychology, 26, 5- 21.

Osofsky, J. D., \& Scheeringa, M. S. (1997). Community and domestic violence exposure: Effects on development and psychopathology. In D. Cicchetti \& S. L. Toth (Eds.), Rochester symposium on developmental psychopathology: Vol.8. Developmental perspectives on trauma: Theory, research, and intervention (pp. 155-180). Rochester, NY: University of Rochester Press.

Pelcovitz, D., Libov, B. G., Mandel, F., Kaplan, S., Weinblatt, M., \& Septimus, A. (1998). Posttraumatic stress disorder and family functioning in adolescent cancer. Journal of Traumatic Stress, 11, 205- 221.

Polan H. J., \& Hofer. M. A. (1999). Psychobiological origins of infant attachment and separation responses. In J. Cassidy \& P. H. Shaver (Eds.), Handbook of attachment: Theory, research, and clinical applications (pp. 162-180). New York: Guilford Press.

Pruett, K. D. (1979). Home treatment for two infants who witnessed their mother's murder. Journal of the American Academy of Child Psychiatry, 18, 647-657.

Reynolds, C. R., \& Richmond, B. 0. (1978). What I think and feel: A revised measure of children's manifest anxiety. Journal of Abnormal Child Psychology, 6, 271-280.

Richman, N., \& Graham, P. J. (1971). A behavioural screening questionnaire for use with 3-yr-old children. Preliminary findings. Journal of Child Psychology and Psychiatry. 12, 5-33.

Rossman, B. B. R., Bingham, R. D., \& Emde, R. N. (1997). Symptomatology and adaptive functioning for children exposed to normative stressors, dog attack, and parental 
violence. Journal of the American Academy of Child and Adolescent Psychiatry, 36, 1089-1097.

Ruchkin, V. V., Eisemann, M., \& Haeggloef, B. (1998). Juvenile male rape victims: Is the level of post-traumatic stress related to personality and parenting? Child Abuse and Neglect, 22, 889-899.

Sack, W. H., Clarke, G. N., \& Seeley, J. (1995). Posttraumatic stress disorder across two generations of Cambodian refugees. Journal of the American Academy of Child and Adolescent Psychiatry, 34, 1160-1166.

Scheeringa, M. S. (1999). Treatment for posttraumatic stress disorder in infants and toddlers. Journal of Systemic Therapies, 18, 20-31.

Scheeringa, M. S., Peebles, C. D. Cook, C. A., \& Zeanah, C. H. (2001). Toward establishing procedural, criterion and discriminant validity for PTSD in early childhood. Journal of the American Academy of Child and Adolescent Psychiatry, 40, 52-60.

Scheeringa, M. S., \& Zeanah, C. H. (1995). Symptom expression and trauma variables in children under 48 months of age. Infant Mental Health Journal, 16, 259-270.

Scheeringa, M. S., Zeanah, C.H., Drell, M.J., \& Larrieu, J. A. (1995). Two approaches to the diagnosis of posttraumatic stress disorder in infancy and early childhood. Journal of the American Academy of Child and Adolescent Psychiatry, 34, 191-200.

Seifer, R., \& Dickstein, S. (2000). Parental mental illness and infant development. In C. H. Zeanah (Ed.), Handbook of infant mental health (2nd ed., pp. 145-160). New York: Guilford Press.

Steele, H., Steele, M., \& Fonagy, P. (1996). Associations among attachment classifications of mothers. fathers, and their infants: Evidence for a relationship-specific 
perspective. Child Development, 67, 541-555.

Terr, L. (1990). Too scared to cry (pp. 178-179). New York: Basic Books.

Warren, S. L., Huston. L., Egeland, B., Sroufe, L. A. (1997). Child and adolescent anxiety disorders and early attachment. Journal of the American Academy of Child and Adolescent Psychiatry, 36, 637-644.

Wasserstein, S. B., \& LaGreca, A. M. (1998). Hurricane Andrew: Parent conflict as a moderator of children's adjustment. Hispanic Journal of Behavioral Sciences, 20. 212-224.

Widom, C. S. (1999). Posttraumatic stress disorder in abused and neglected children grown up. American Journal of Psychiatry, 156, 1223-1229.

Zeanah, C. H., Boris, N. W., \& Larrieu, J. A. (1997). Infant development and developmental risk: A review of the past JO years. Journal of the American Academy of Child and Adolescent Psychiatry. 36, 165-178.

Zeanah, C. H., Boris, N. W., \& Scheeringa, M. S. (1997). Psychopathology in infancy. Journal of Child Psychology, Psychiatry, and Allied Disciplines, 38, 81-99.

Zeanah, C. H., \& Burk, G. S. (1984). A young child who witnessed her mother's murder: Therapeutic and legal considerations. American Journal of Psychotherapy, 38, 132145.

Zeanah, C. H., Larrieu. J. A., Heller, S.S. \& Valliere, J. (2000). Infant-parent relationship assessment. In C. H. Zeanah (Ed.), Handbook of infant mental health (2nd ed., pp. 222-235). New York: Guilford Press.

Zeanah, C. H. \& Scheeringa, M. S. (1996). Evaluation of posttraumatic symptomatology in infants and young children exposed to violence. Zero to Three. Bulletin of Zero 
to Three/The National Center, 16, 9-14.

Zero to Three (1994). Diagnostic classification: 0-3. Arlington, VA: Zero to Three. 
Table 1. Studies that Examined the Association Between Parental/Family Functioning and Childrens' Symptomatology Following Traumas

\begin{tabular}{|c|c|c|c|c|c|}
\hline Citation & $\mathrm{N}$ & Age range & Type of trauma & Parental/family variable & Child outcomes \\
\hline Burke et al., 1982 & 64 & $\begin{array}{l}\text { Not stated } \\
\text { (mean } 6 \text { yrs) }\end{array}$ & $\begin{array}{l}\text { Blizzard and } \\
\text { flood }\end{array}$ & $\begin{array}{l}\text { Parental denial of children’s } \\
\text { symptoms per Conners Teacher } \\
\text { Questionnaire (Parental } \\
\text { Conners Q. was not related) }\end{array}$ & $\begin{array}{l}\text { Elevated child aggression and } \\
\text { antisocial acts }\end{array}$ \\
\hline $\begin{array}{l}\text { Handford et al., } \\
1986\end{array}$ & 35 & $6-19$ & $\begin{array}{l}\text { Nuclear power } \\
\text { plant accident. }\end{array}$ & $\begin{array}{l}\text { Discrepancy between mother } \\
\text { and father reactions (Parental } \\
\text { MMPI was not related) }\end{array}$ & $\begin{array}{l}\text { Higher child “intensity of } \\
\text { reaction” score (CMAS was not } \\
\text { related) }\end{array}$ \\
\hline $\begin{array}{l}\text { Cornely \& } \\
\text { Bromet, } 1986\end{array}$ & 565 & 3 & $\begin{array}{l}\text { Nuclear power } \\
\text { plant accident }\end{array}$ & $\begin{array}{l}\text { Maternal history of any } \\
\text { disorder, } \\
\text { Elevated maternal SCL-90 } \\
\text { score }\end{array}$ & Elevated BSQ score \\
\hline McFarlane, 1987 & 446 & Mean 8.2 & Brushfire & $\begin{array}{l}\text { Maternal overprotectiveness, } \\
\text { Maternal intrusive thoughts, } \\
\text { Family being split up, } \\
\text { Increased family irritability, } \\
\text { Increased family withdrawal }\end{array}$ & $\begin{array}{l}\text { Increased number of child } \\
\text { PTSD-like symptoms (modified } \\
\text { Rutter questionnaires) }\end{array}$ \\
\hline $\begin{array}{l}\text { Breton et al., } \\
1993\end{array}$ & 43 & $6-11$ & $\begin{array}{l}\text { Fire and toxic } \\
\text { smoke }\end{array}$ & $\begin{array}{l}\text { Fathers' elevated PSI score } \\
\text { (Parental psychiatric history not } \\
\text { related, Dyadic Adjustment } \\
\text { Scale score not related) }\end{array}$ & $\begin{array}{l}\text { Elevated number of PTSD } \\
\text { symptoms (BSQ scores not } \\
\text { related) }\end{array}$ \\
\hline $\begin{array}{l}\text { Famularo et al., } \\
1994\end{array}$ & 109 & $5-12$ & Maltreatment & Presence of maternal PTSD & Presence of PTSD \\
\hline $\begin{array}{l}\text { Koplewicz et al., } \\
1994\end{array}$ & 22 & $\sim 7-11$ & $\begin{array}{l}\text { World Trade } \\
\text { Center bombing }\end{array}$ & Elevated maternal PTS-RI score & Elevated PTS-RI score \\
\hline Sack et al., 1995 & 118 & $13-25$ & $\begin{array}{l}\text { Refugees from } \\
\text { Cambodian } \\
\text { conflict }\end{array}$ & Presence of PTSD in any parent & Presence of PTSD \\
\hline Laor et al., 1996 & 72 & $3-5$ & $\begin{array}{l}\text { Displaced by } \\
\text { missile attacks }\end{array}$ & Less family cohesion (FACES) & $\begin{array}{l}\text { Elevated CBCL internalizing } \\
\text { score }\end{array}$ \\
\hline
\end{tabular}




\begin{tabular}{|c|c|c|c|c|c|}
\hline & & & & score & score. Elevated PCASS score \\
\hline Laor et al., 1997 & 51 & $5-7$ & $\begin{array}{l}\text { Displaced by } \\
\text { missile attacks }\end{array}$ & $\begin{array}{l}\text { Elevated maternal SCL-90 } \\
\text { score, } \\
\text { Maternal intrusive thoughts, } \\
\text { Maternal avoidance symptoms }\end{array}$ & Elevated PTS-RI score \\
\hline \multirow[t]{2}{*}{$\begin{array}{l}\text { Rossman et al., } \\
1997\end{array}$} & 86 & $4-9$ & $\begin{array}{l}\text { Dog attack, } \\
\text { parental } \\
\text { violence, and } \\
\text { mild stress }\end{array}$ & $\begin{array}{l}\text { Less parental "supportiveness" } \\
\text { of the child }\end{array}$ & $\begin{array}{l}\text { Elevated PTS-RI score, } \\
\text { Elevated CDC score, } \\
\text { Elevated CBCL externalizing } \\
\text { score }\end{array}$ \\
\hline & & & & Elevated maternal PTS-RI score & $\begin{array}{l}\text { Elevated child PTS-RI score, } \\
\text { Elevated CBCL internalizing } \\
\text { score }\end{array}$ \\
\hline $\begin{array}{l}\text { Kilpatrick \& } \\
\text { Williams, } 1998\end{array}$ & 20 & $6-12$ & $\begin{array}{l}\text { Domestic } \\
\text { violence }\end{array}$ & $\begin{array}{l}\text { (Maternal emotional problems } \\
\text { [GHQ] not related) }\end{array}$ & (PTS-RI score not related) \\
\hline Wasserstein \& & $89(n=15$ & $4^{\text {th }}-6^{\text {th }}$ & Hurricane & Elevated mother-father conflict & Elevated PTS-RI score, \\
\hline LaGreca, 1998 & Hispanic) & graders & Andrew & & Elevated RCMAS score \\
\hline $\begin{array}{l}\text { Pelcovitz et al., } \\
1998\end{array}$ & 23 & $14-23$ & Cancer & $\begin{array}{l}\text { Presence of maternal PTSD, } \\
\text { Elevated chaos in family } \\
\text { (FACES III; Maternal SCL-90 } \\
\text { not related) }\end{array}$ & Presence of PTSD \\
\hline $\begin{array}{l}\text { Ruchkin et al., } \\
1998\end{array}$ & 11 & $15-17$ & Male rape & $\begin{array}{l}\text { Decreased paternal warmth, } \\
\text { Increased paternal rejection } \\
\text { (Maternal warmth not related, } \\
\text { Maternal rejection not related) }\end{array}$ & Elevated PTS-RI score \\
\hline Ajdukovic, 1998 & 45 & $14-19$ & War in Croatia & $\begin{array}{l}\text { Child's perception of parental } \\
\text { anxiety }\end{array}$ & $\begin{array}{l}\text { Elevated number of PTSD } \\
\text { symptoms }\end{array}$ \\
\hline \multirow[t]{2}{*}{$\begin{array}{l}\text { Deblinger et al., } \\
1999\end{array}$} & 100 & $7-13$ & Sexual abuse & Elevated maternal BDI score & $\begin{array}{l}\text { Elevated number of PTSD } \\
\text { symptoms, Elevated CBCL } \\
\text { internalizing score }\end{array}$ \\
\hline & & & & Maternal use of guilt & $\begin{array}{l}\text { Elevated number of PTSD } \\
\text { symptoms }\end{array}$ \\
\hline
\end{tabular}




\author{
Anxiety-provoking parenting \\ methods
}

Perceived parental rejection
Elevated number of PTSD

symptoms

Elevated CBCL externalizing

score

Elevated depression score

Note: BSQ: Behavior Screening Questionnaire; SCL-90: Symptom Checklist 90; PSI: Psychiatric Symptom Index; PTS-RI: Posttraumatic Stress Reaction Index; PCASS: Preschool Children's Assessment of Stress Scale; GHQ: General Health Questionnaire; RCMAS: Revised Children’s Manifest Anxiety Scale; BDI: Beck Depression Inventory. 